\title{
Osteopatologias e alterações dentárias em Otaria byronia (Pinnipedia, Otariidae) da costa do Rio Grande do Sul, Brasil
}

\author{
Patrícia Rodrigues Braunn \& Jorge Ferigolo
}

\author{
Museu de Ciências Naturais, Fundação Zoobotânica do Rio Grande do Sul, Rua Dr. Salvador França, 1427, 90690-000, Porto \\ Alegre, RS, Brasil. (ferigolo@plug-in.com.br)
}

\begin{abstract}
Osteopathologies and tooth alterations in Otaria byronia (Pinnipedia, Otariidae) from Rio Grande do Sul coast, Brazil. Bone diseases and tooth alterations in 47 specimens of Otaria byronia (Blainville, 1820), from southern Brazilian coast, were analized. Tooth wear and the associated bone pathologies were determined, as well as their percentuals. The main infection was osteomyelitis associated with tooth alterations, such as fractures and attrition, both of them exposing the pulp chamber. Tooth attrition increases with age, favoring fractures and their complications, including osteomyelitis, causing a high frequency of them in specimens presenting more pronounced tooth wear. In one specimen tuberculosis was found in the maxilla, perhaps primarily pulmonary. The high frequency of enamel hypoplasia might reflect cyclic food deficit. Infections and tooth fractures might be related to behaviour, such as fishermen interaction, territorial fighting, and accidents during food capture.
\end{abstract}

KEYWORDS. Otaria, pathology, tooth lesions, enamel hypoplasia.

\section{INTRODUÇÃO}

Otaria byronia (Blainville, 1820), o leão-marinho sul-americano, é o otarídeo mais freqüente no extremo sul do Brasil, sendo este o limite norte de sua distribuição habitual no Oceano Atlântico (Rosas et al., 1994), tendo ampla faixa de distribuição nas zonas costeiras da América do Sul (KInG, 1983). No Rio Grande do Sul, a maioria dos indivíduos observados são machos subadultos e adultos, que costumam freqüentar a Reserva Ecológica da Ilha dos Lobos, em frente à cidade de Torres e o Molhe Leste da Barra em Rio Grande (RS), não havendo colônias reprodutivas no Brasil (RosAs et al., 1994).

Patologias ósseas e lesões dentárias em pinipédios têm sido pouco registradas. MorejoHn (1969) descreveu um caso de deformidade na coluna vertebral e osteonecrose da cintura pélvica e fêmur em um macho adulto de Zalophus californianus (Lesson, 1828), além de importante desgaste dos caninos e incisivos. BARTSCH \& FRUEH (1971) descreveram lesões inflamatórias junto ao canino de uma morsa, causadas por fraturas decorrentes do hábito destes animais se apoiarem sobre suas grandes presas para se deslocarem em rochedos, o que leva freqüentemente a fraturas e infecções secundárias. STROUD \& ROFFE (1979) registraram a morte de um macho adulto de Phoca vitulina (L., 1758) devido a sérias fraturas e lesões dentárias, entre elas intenso desgaste, lesão periodontal e outras múltiplas lesões ósseas. Junin \& CASTELlo (1995) observaram osteomielite no crânio de Hydrurga leptonyx (Blainville, 1820), a foca leopardo. ERB et al. (1996) descreveram lesões dentárias e mandibular no sincrânio de um Arctocephalus gazella (Peters, 1875), entre elas, luxação da sínfise mandibular, osteomielite em ambos os dentários e periostite no maxilar esquerdo. Tais alterações, segundo os autores, estão relacionadas com ferimentos decorrentes de lutas entre machos territoriais, hábito bastante comum entre pinipédios. DREHMER \& FERIGOLO (1996, 1998) observaram anomalias e patologias dentárias em espécimes de Arctocephalus G. Saint-Hilaire \& Cuvier, 1826; descreveram agressões e patologias ósseas em um macho de Mirounga leonina (L., 1758), tendo sido constatadas osteomielite mandibular crônica, fratura de alguns dentes pós-caninos, infecção relacionada a abcesso periapical e provável doença de Scheuermann em vértebras lombares.

Objetiva-se aqui descrever alterações ósseas e dentárias em espécimes de $O$. byronia, bem como discutir as possíveis relações entre tais alterações; determinar as relações entre os níveis de desgaste dentário com o sexo, idade e tipos de patologias, e analisar relações entre as patologias apresentadas e os padrões comportamentais da espécie.

\section{MATERIAL E MÉTODOS}

O material ósseo é constituído por 47 espécimes de O. byronia (tab. I), tombados na Coleção de Mastozoologia, Museu de Ciências Naturais (MCN), Fundação Zoobotânica do Rio Grande do Sul, Porto Alegre, coletados no litoral do Rio Grande do Sul, desde Cidreira até Santa Vitória do Palmar, no inverno dos anos de 1990, 1992, 1994 a 1996 e no outono de 1998.

Foram analisados 39 sincrânios e 8 crânios, correspondendo a 31 machos (ð), 11 fêmeas (†) e 5 nãodeterminados $(\varnothing)$. Apenas 33 espécimes fizeram parte dos cálculos dos percentuais, isto porque os demais são crânios incompletos, sem a porção rostral e/ou sem dentes.

Material examinado. BRASIL, Rio Grande do Sul: Santa Vitória do Palmar, 6 đ’, 3 ๆ, $2 \varnothing$, IX.1990, J. Ferigolo col. (MCN $2459,2460,2462,2521,2524,2525,2526,2528,2533,2534$, 2564); 4 o, 1 f, 17.IX.1994, C. Drehmer col. (MCN 2610, 2612, 2616, 2618, 2619); 2 đ, 3 ๆ, $1 \varnothing$, 18.IX.1995, C. Drehmer (MCN 2697, 2698, 2700, 2701, 2703, 2729); Mostardas, 1 ॐ, 22.VIII.1992, C. Drehmer (MCN 2505); Rio Grande, 3 o, 1 क, 16.IX.1994, C. Drehmer (MCN 2601-2604); 2 హ, $1 \varnothing$, 17.IX.1994, C. Drehmer (MCN 2622, 2624, 2560); 3 o, VII.1997, E. Borsato col. (MCN 2806, 2807, 2823); 1 o, 1 f, VII.1998, E. Borsato 
Tabela I. Osteopatologias e estágios de alterações dentárias em 47 espécimes de Otaria byronia do litoral do Rio Grande do Sul (1, osteomielite; 2, tuberculose; 3, lesão periapical; 4, fratura ou perda dentária; 5, hipoplasia de esmalte; A, adulto; F, fêmea; J, jovem; M, macho; S, subadulto; -, não determinado ou ausente; estágios de desgaste dentário: 1, atrição ausente ou pequena na coroa dentária; 2, atrição com fraturas apenas do esmalte; 3, completo desgaste das cúspides com ou sem exposição da cavidade pulpar).

\begin{tabular}{cccccccccc}
\hline $\begin{array}{c}\text { Coleção } \\
\text { MCN }\end{array}$ & Sexo & $\begin{array}{c}\text { Faixa } \\
\text { etária }\end{array}$ & $\begin{array}{c}\text { Desgaste } \\
\text { dentário }\end{array}$ & Osteopatologia & $\begin{array}{c}\text { Coleção } \\
\text { MCN }\end{array}$ & $\begin{array}{c}\text { Sexo } \\
\text { Faixa } \\
\text { etária }\end{array}$ & $\begin{array}{c}\text { Desgaste } \\
\text { dentário }\end{array}$ & Osteopatologia \\
\hline 2459 & M & A & 3 & 4 & 2624 & M & S & 1 & 5 \\
2460 & M & A & 3 & 1,4 & 2629 & M & A & 3 & $1,4,5$ \\
2462 & F & A & 3 & 4,5 & 2686 & M & - & 2 & 5 \\
2505 & M & A & 3 & $1,4,5$ & 2691 & F & S & 2 & 5 \\
2521 & F & - & 2 & 4,5 & 2693 & M & - & 1 & - \\
2524 & - & - & - & - & 2695 & M & - & 1 & 5 \\
2525 & M & - & 2 & 5 & 2696 & M & S & 2 & 5 \\
2526 & M & - & - & - & 2697 & M & A & 3 & 5 \\
2528 & M & - & - & - & 2698 & F & S & 2 & 5 \\
2533 & F & - & - & - & 2700 & M & A & 3 & 4,5 \\
2534 & - & - & - & - & 2701 & F & A & 3 & 4,5 \\
2560 & - & - & - & - & 2703 & F & A & 3 & $1,4,5$ \\
2564 & M & A & - & 4 & 2704 & F & - & - & - \\
2601 & M & S & 2 & 5 & 2729 & - & - & - & - \\
2602 & M & - & 2 & 5 & 2806 & M & A & 3 & $1,2,4,5$ \\
2603 & M & S & 2 & 5 & 2807 & M & A & 3 & $1,4,5$ \\
2604 & F & - & 2 & 1,5 & 2823 & M & - & - & - \\
2610 & M & S & 1 & 5 & 2832 & M & A & 3 & $1,3,4,5$ \\
2612 & M & S & 2 & 5 & 2837 & M & - & - & - \\
2616 & M & S & 2 & 5 & 2838 & M & - & - & - \\
2618 & F & J & - & - & 2846 & M & - & - & - \\
2619 & M & S & 2 & 5 & 2885 & - & - & 1 & - \\
2622 & M & - & 1 & 5 & 2966 & F & - & 3 & 1,4 \\
& & & & & 2990 & M & - & 3 & $1,4,5$ \\
\hline
\end{tabular}

(MCN 2832, 2966); $1 \varnothing, 25 . I V .1998$, E. Borsato (MCN 2885); São José do Norte, 1 $\%$, 18.IX.1994, C. Drehmer (MCN 2629); 3 §, 1 q, 17.IX.1995, C. Drehmer (MCN 2691, 2693, 2695, 2696); 1 †, 18.IX.1995, C. Drehmer (MCN 2704); 1 đ, 10.VIII.1996, C. Drehmer (MCN 2990); Tavares, 1 ơ, 16.IX.1995, C. Drehmer (MCN 2686); 1 ॐ (MCN 2837); 1 హ, (MCN 2846); 1 హ, VII.1991, E. Borsato (MCN 2838).

A preparação osteológica seguiu DreHMER \& Ferigolo (1996). A sexagem foi realizada em campo; quando o estado de decomposição estava avançado, utilizou-se um caráter de dimorfismo sexual, que é o ângulo da coroa do canino no seu plano médio, onde os machos têm o diâmetro da coroa maior que o das fêmeas, propiciando um ângulo maior (CRESPO, 1984). A crista sagital foi analisada para auxiliar na identificação dos machos e fêmeas, adultos e jovens (DREHMER \& FERIGOLO, 1996). A identificação das osteopatologias e alterações dentárias foi realizada através de exame macroscópico direto e, quando necessário, sob estereomicroscópio.

A estimativa qualitativa dos estágios de desgaste dentário de cada espécime foi feita por categorias: estágio 1, atrição ausente ou pequena na coroa dentária (fig. 1); estágio 2, atrição com fraturas do esmalte apenas (figs. 2, 3); estágio 3, completo desgaste das cúspides com ou sem exposição da câmara pulpar (figs. 4, 5). As fraturas dentárias em vida foram diferenciadas das pós-morte porque pelo uso dos dentes as superfícies fraturadas se tornam arredondadas e polidas. Procedeu-se o cálculo dos percentuais das alterações em cada um dos três estágios de desgaste dentário. Foi realizada apenas uma análise qualitativa das diferenças existentes entre
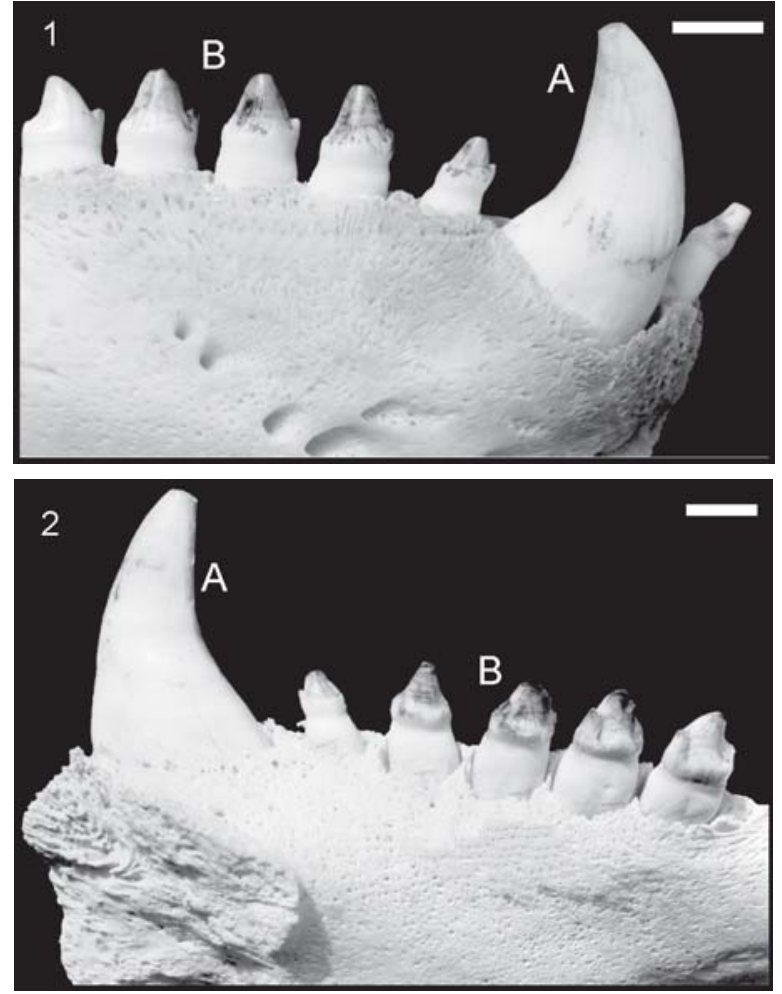

Figs. 1, 2. Otaria byronia: 1, porção anterior do dentário direito (MCN 2622), vista lateral: canino (A) e pós-caninos (B) em estágio de desgaste 1, com pequena atrição na coroa dentária; 2, porção anterior do dentário direito (MCN 2696), vista medial: caninos e pós-caninos em estágio de desgaste 2, com fraturas de esmalte. Escalas $10 \mathrm{~mm}$. 



Figs. 3-5. Otaria byronia: 3, canino inferior direito (MCN 2696), vista labial: fratura do esmalte (flecha), estágio de desgaste $2 ; 4$, mandíbula (MCN 2460), vista oclusal parcial: incisivos e caninos em estágio de desgaste 3 (A); incisivos fraturados no nível cervical (B); fechamento parcial do alvéolo do terceiro pós-canino direito (C), indicando perda dentária em vida; 5, crânio (MCN 2460), porção anterior, vista ventral: incisivos, caninos e pós-caninos apresentando estágio de desgaste 3 (A); incisivos fraturados no colo (B). Escalas $10 \mathrm{~mm}$.

alterações em machos e fêmeas, tendo em vista o reduzido tamanho amostral, sobretudo de fêmeas, insuficiente para testar a significância das diferenças.

\section{RESULTADOS}

As principais alterações dentárias foram fraturas do esmalte, perda dentária e lesão periapical (figs. 6, 7). Nenhum espécime do estágio 1 de desgaste apresentou alterações dentárias e, no estágio 2 , a freqüência foi de $7,69 \%(n=1)$, sendo observada maior freqüência $(100 \%$, $\mathrm{n}=14$ ) de espécimes com alterações dentárias no estágio 3 (tab. II), em indivíduos adultos (tab. I). A lesão periapical foi observada apenas em um espécime do estágio de desgaste 3. A frequiência de alterações dentárias nos machos foi de $32,26 \%(n=10)$, e as fêmeas de 45,45\% ( $n=5)$.
Em nenhum espécime do estágio 1 foram observadas lesões de origem infecciosa, enquanto que no estágio 2 a freqüência foi de $7,69 \%(n=1)$, sendo a frequiência maior no estágio $3(69,23 \%, n=9)$. As infecções ósseas associadas a alterações dentárias nos machos, como a osteomielite, apresentaram freqüência de 22,58\% $(n=7)$ e em fêmeas $(27,27 \%, n=3)$ (fig. 8$)$.

Outra osteopatologia foi a tuberculose, observada no crânio MCN 2806, com lesões características de uma infecção crônica. Há envolvimento da região craniana propriamente dita, com neoformação óssea periosteal em ambos parietais, processos pós-orbitais dos frontais e região supraoccipital, sugestiva de ossificação de abcessos tuberculosos (fig. 9). Há também uma lesão lítica circular, de aproximadamente dois centímetros de diâmetro, próxima ao processo zigomático, com as bordas 

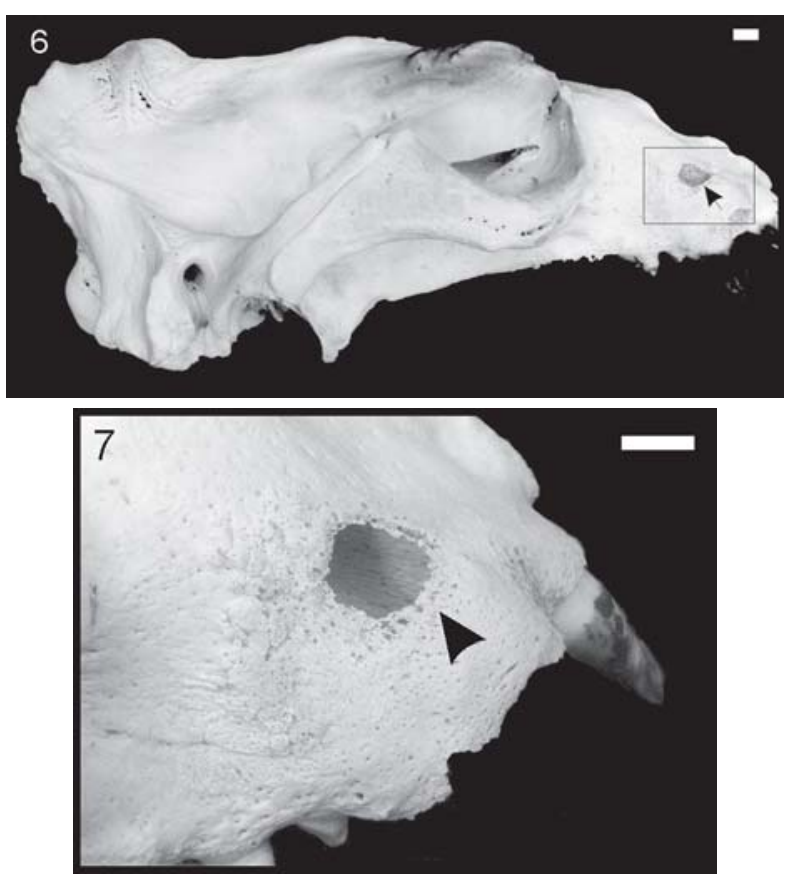

Figs. 6, 7. Otaria byronia (MCN 2832): 6, crânio, vista lateral: lesão periapical (setas); 7, maxilar direito, vista lateral; detalhe da lesão periapical. Escalas $10 \mathrm{~mm}$.

arredondadas, do tipo "roída por traça", e que perfura o maxilar até o maxilo-turbinal (fig. 10).

A hipoplasia de esmalte foi a alteração dentária que apresentou a maior freqüência $(87,89 \%, n=28)$ (tab. II; fig. 11), tendo sido, nos diferentes estágios de desgaste dentário: estágio $1(100 \%, \mathrm{n}=4)$, estágio $2(100 \%, \mathrm{n}=13)$, e estágio $3(76,92 \%, \mathrm{n}=11)$ (tab. II). Observou-se certa similaridade nos resultados em relação à freqüêência da hipoplasia de esmalte em machos $(67,74 \%, \mathrm{n}=21)$ e fêmeas $(63,64 \%, \mathrm{n}=7)$.
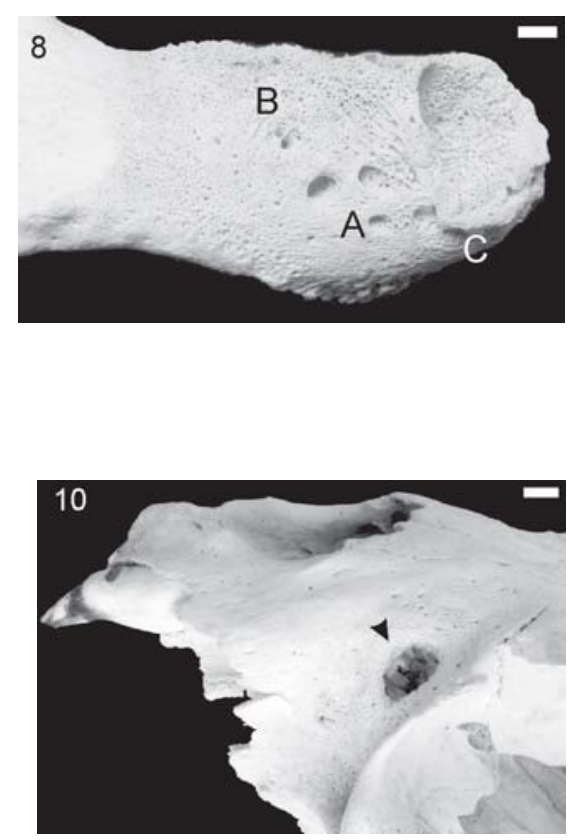

Figs. 8-11. Otaria byronia: 8, dentário direito (MCN 2807), vista lateral: cloacas da osteomielite (A); destruição da cortical óssea (B); fratura consolidada na margem labial do alvéolo do canino direito (C); 9, crânio (MCN 2806), vista dorsal: neoformação óssea periosteal em ambos os parietais (setas); 10, rostro (MCN 2806), vista parcial lateral esquerda: lesão lítica arredondada, perfurando o maxilar até o maxilo-turbinal, típica de tuberculose óssea (seta). 11, canino esquerdo (MCN 2696), vista labial: orifícios ("pits") devidos à hipoplasia de esmalte (setas). Escalas 10 mm. 
mente peixes ósseos, o que deve levar a um maior desgaste e fraturas durante a alimentação, além do desgaste natural resultante da oclusão dentária, que se acentua em indivíduos com mais idade.

Otaria byronia freqüentemente apresenta seixos no estômago, denominados gastrólitos (HAMiLton, 1934). Existem controvérsias em relação à função dos gastrólitos, sendo que uma hipótese sustenta que eles proporcionariam um efeito estabilizador durante a natação e mergulho, ou que auxiliariam na trituração do alimento no estômago, diminuindo a sensação de fome nos períodos de escassez de alimento e auxiliando na defesa contra parasitas estomacais ou, ainda, seriam ingeridos acidentalmente durante a alimentação. Há especulações sobre o fato de que estes animais ao ingerirem rochas sofreriam fraturas dentárias. Segundo DREHMER \& FERIGOLO (1996), esta possibilidade é remota, já que a ingestão não deve ser acidental, mas intencional, o que não provocaria fraturas. Outro aspecto que pode estar relacionado com fraturas dentárias é o característico comportamento agressivo intra-específico dos machos adultos durante disputas por território e fêmeas no período de acasalamento. Vários trabalhos mencionam ferimentos decorrentes destas lutas, incluindo caninos fraturados ou avulsionados, ferimentos devido a mordidas e infecções secundárias, entre outras (Hamilton, 1934; Stroud \& RofFe, 1979; BaKer, 1987; Campagna \& Le Boeuf, 1988; BaKer \& McCann, 1989; ReEves et al., 1992; Drehmer \& Ferigolo, 1996, 1998; ЕRB et al., 1996).

A osteomielite bacteriana maxilo-mandibular relacionada com lesões dentárias foi a principal alteração infecciosa encontrada, já que as fraturas e perdas dentárias podem expor a câmara pulpar, possibilitando a entrada de patógenos, que iniciam um processo infeccioso. Por esta razão, a frequiência de espécimes no estágio 3 é maior, uma vez que um grau maior de desgaste torna os dentes mais suscetíveis a fraturas.

A similaridade da freqüência de hipoplasia de esmalte em machos e fêmeas poderia sugerir uma ausência de diferenças entre os mesmos nos ciclos carenciais durante as primeiras fases de seu desenvolvimento. A hipoplasia, por ser devida a distúrbios durante a formação do esmalte, sua freqüência obviamente é a mesma nos diferentes estágios de desgaste dentário, sendo que a aparente redução da frequiência no estágio 3, pode ser devida à redução na altura dos dentes, quando desgastados.

Os tipos de alterações dentárias e infecções ósseas associadas nos machos corroboram a hipótese de acidentes durante lutas territoriais. Em fêmeas, é possível observar que as lesões dentárias e enfermidades infecciosas associadas são principalmente perdas de incisivos e pós-caninos, provavelmente durante a alimentação. Em machos, além de fraturas e desgaste avançado, há avulsionamento dos caninos, o que teria exigido um trauma bastante importante tanto para fraturálos quanto para avulsioná-los, devido à robustez dos mesmos. MoreJohn (1969) relatou desgaste avançado dos caninos em Zalophus californianus e o relaciona com o debilitado estado de saúde do animal, que impossibilitado de caçar, teria partido para outros meios de captura do alimento, como "raspar" moluscos nos rochedos com os dentes.

A osteomielite é uma infecção do osso e da medula óssea, originada em resposta a um processo infeccioso causado por microorganismos como bactérias, por extensão direta das infecções de tecidos moles adjacentes ou fraturas expostas. Septicemia e mesmo a morte podem ocorrer em indivíduos que apresentam abscessos periapicais, com ou sem osteomielite adjacente (ORTNER \& Putschar, 1981). Isto pode ter ocorrido nos espécimes que apresentaram sinais de osteomielite bacteriana, tendo a morte dos indivíduos se dado em razão da disseminação hemática de patógenos. Todavia, toda e qualquer tentativa de correlação das alterações ósseas e dentárias aqui apresentadas com as causas de morte é meramente especulativa, pois os animais não foram submetidos à necropsia quando de sua coleta, nem examinados bacteriologicamente seus órgãos.

Numerosos trabalhos sobre pinipédios apontam causas de morte, desde fatores climáticos, altos níveis de infecção parasitária (CORDES \& O'HARA, 1979; STROUD \& ROFFe, 1979), e até doenças de origem bacteriana (BAKER, 1984; BAKER \& MACCANN, 1989). Interações com a atividade pesqueira, lutas territoriais e acidentes durante deslocamentos destes animais sobre rochedos são alguns dos aspectos comportamentais que provocam lesões que podem originar infecções secundárias, por extensão de ferimentos contaminados, ou infecções ósseas.

DREHMER \& FERIGOLO (1998) analisaram a relação existente entre um indivíduo macho de Mirounga leonina no litoral gaúcho, fora de sua área usual de distribuição, e seu debilitado estado de saúde. Os autores comentaram a possibilidade de haver relação com o fato conhecido de animais doentes afastarem-se do convívio dos seus semelhantes, como acontece entre elefantes, búfalos e cervídeos.

Quanto ao caso de tuberculose aqui descrito, a hipótese mais provável é a de uma disseminação hematógena da infecção do aparelho respiratório para o esqueleto. Nos registros de tuberculose em otarídeos silvestres na Austrália (Cousins et al., 1993) e Argentina (BERNARDELLi et al., 1996), as alterações patológicas eram principalmente pequenos e numerosos abscessos nos pulmões, lesões caseosas arredondadas de até 40 milímetros de diâmetro, bem como lesões calcificadas. Cousins et al. (1993) afirmaram que os casos de tuberculose no sul da Austrália foram adquiridos por inalação do bacilo, uma vez que os pulmões eram sempre o primeiro foco de infecção.

Agradecimentos. À FAPERGS e à Fundação Zoobotânica do Rio Grande do Sul, pelo financiamento e suporte ao desenvolvimento deste trabalho. À colega Ana Maria Ribeiro (MCN/FZBRS), por seu incentivo e auxílio na confecção das fotografias.

\section{REFERÊNCIAS BIBLIOGRÁFICAS}

BAKER, J. R. 1984. Mortality and morbidity in Grey seal pups (Halichoerus grypus). Studies on its causes, effects of environment, the nature and sources of infectious agents and the immunological status of pups. Journal of Zoology, London, 203:23-48.

1987. Causes of mortality and morbidity in wild juvenile and adult grey seals (Halichoerus grypus). British Veterinary 
Journal, London, 143:203-220.

BakeR, J. R. \& McCANn, T. S. 1989. Pathology and bacteriology of adult male Antarctic fur seals, Arctocephalus gazella, dying at Bird Island, South Georgia. British Veterinary Journal, London, 145:263-275.

Bartsch, R. C. \& Frueh, R. J. 1971. Alveolitis and pulpitis of a canine tooth in a walrus. The Journal of the American Veterinary Medical Association, New York, 159(5):575577.

Bernardelli, A.; Bastida, R. et al. 1996. Tuberculosis in sea lions and fur seals from the south-western Atlantic coast. Revue Scientifique et Technique Office International des Épizooties, Paris, 15(3):985-1005.

Campagna, C. \& Le Boeuf, B. J. 1988. Reproductive behaviour of southern sea lions. Behaviour, Leiden, 104(3-4):233-261.

Cordes, D. O. \& O'Hara, P. J. 1979. Diseases of captive marine mammals. New Zealand Veterinary Journal, Wellington, 27:147-150.

Cousins, D. V; Williams, S. N. et al. 1993. Tuberculosis in wild seals and characterization of the seal bacillus. Australian Veterinary Journal, Sydney, 70(3):92-97.

Crespo, E. A. 1984. Dimorfismo sexual en los dientes caninos y en los craneos del lobo marino del sur, Otaria flavescens (Shaw, 1800) (Pinnipedia, Otariidae). Revista del Museo Argentino de Ciencias Naturales "Bernardino Rivadavia", Zool., Buenos Aires, 13(25):245-257.

Drehmer, C. J. \& Ferigolo, J. 1996. Anomalias e patologias dentárias em Arctocephalus G. Saint-Hilaire \& Cuvier (Pinnipedia, Otariidae) da costa do Rio Grande do Sul, Brasil. Revista Brasileira de Zoologia, Curitiba, 13(4):857-865. 1998. Ocorrência de Mirounga leonina Linnaeus (Pinnipedia, Phocidae) no extremo sul do Brasil: agressão e patologias.
Revista Brasileira de Zoologia, Curitiba, 15(4):1061-1068. Erb, E.; Shaughnessy, P. D. \& Norman, R. J. De B. 1996. Dental and mandibular injury in an antartic fur seal, Arctocephalus gazella, at Heard Island, southern ocean. Journal of Wildlife Diseases, Laramie, 32(2):376-380.

Hamilton, J. E. 1934. The southern sea lion, Otaria byronia (de Blainville). Discovery Reports, Cambridge, 8:269-318.

Junin, M. \& Castello, H. P. 1995. Osteomyelitis of the skull in a leopard seal, Hydrurga leptonyx. Marine Mammal Science, Lawrence, 11(3):403-406.

KInG, J. E. 1983. Seals of the World. Oxford, Oxford University. 239p.

Morejohn, G. V. 1969. Vertebral column deformity and osteonecrosis of pelvis and femur in the California sea lion. California Fish Game, Sacramento, 55:323-326.

Ortner, D. J. \& Putschar, W. G. J. 1981. Identification of pathological conditions in human skeletal remains. Smithsonian Contributions to Anthropology, Washington, 28:1-479.

Reeves, R. R.; Stewart, B. S. \& Leatherwood, S. 1992. The Sierra Club handbook of seals and sirenians. San Francisco, Sierra Club Books. 359p.

Rosas, F. C. W.; Pinedo, M. C. et al. 1994. Seasonal movements of the South American sea lion (Otaria flavescens Shaw) off the Rio Grande do Sul coast, Brazil. Mammalia, Paris, 58(1):51-59.

Stroud, R. K. \& Roffe, T. J. 1979. Causes of death in marine mammals stranded along the Oregon Coast. Journal Wildlife Diseases, Laramie, 15:91-97.

VAN VALKENBURGH, B. 1988. Incidence of tooth breakage among large, predatory mammals. American Naturalist, Chicago, 131(2):291-302. 